\title{
Modulation Spaces on the Euclidean $n$-Space
}

\author{
H. Tŕiebel
}

Die Arbeit beschäftigt sich mit dem Problem der Spuren von Funktionen aus Modulationsräumen auf der Grundlage der Fourier-Analysis und der Maximalungleichungen.

В рап̆оте рассматривается задача о следах функциї из пространств модуляций на основании анализа Фурье и максимальных неравенств.

The paper deals with the problem of the traces of functions belonging to modulation spaces on the basis of Fourier analysis and maximal inequalities.

\section{Introduction}

Let $\varphi(x) \geqq 0$ be a compactly supported infinitely differentiable function on the euclidean $n$-space $\mathbf{R}_{n}$. Iset

$$
\mathbf{Z}_{n}=\left\{k \mid k \in \mathbf{R}_{n}, k=\left(k_{1}, \ldots, k_{n}\right), k_{j} \text { integers }\right\}
$$

and $\varphi_{k}(x)=\varphi(x-k)$ with $k \in \mathbf{Z}_{n}$. We assume that $\sum_{k \in \mathbf{Z}_{n}} \varphi_{k}(x) \equiv 1$ in $\mathbf{R}_{n}$ (smooth resolution of unity in $\mathbf{R}_{n}$ ). Let $a=\left\{a_{k}\right\}_{k \in \mathbf{Z}_{n}}$ be a sequence of positive numbers. The paper deals with the spaces $B_{p, q}^{\mathrm{a}}\left(\mathbf{R}_{n}\right)$ and $F_{p, q}^{\mathrm{a}}\left(\mathbf{R}_{n}\right)$, which are characterized by the quasinorms

$$
\left(\sum_{k \in Z_{n}} a_{k}^{q}\left\|F^{-1}\left[\varphi_{k} F f\right] \mid L_{p}\left(\mathbf{R}_{n}\right)\right\|^{q}\right)^{1 / q}
$$

and

$$
\|\left(\sum_{k \in Z_{n}} a_{k}^{q}\left|\left(\left.F^{-1}\left[p_{k} F f\right](\cdot)\right|^{q}\right)^{1 / q}\right| L_{p}\left(\mathbf{R}_{n}\right) \|\right.
$$

respectively. Here $0<p, q \leqq \infty$ (with $p<\infty$ in the case of the spaces $F_{p . q}^{\mathfrak{a}}\left(\mathbf{R}_{n}\right)$ ). $F^{\prime}$ and $F^{-1}$ stand for the Fourier transform and its inverse, respectively, on the Schwart\% space $S\left(\mathbf{R}_{n}\right)$. For our purpose it is sufficient to assume that $f$ belongs to $S\left(\mathbf{R}_{n}\right)$ with supp $F f$ compact. By a suggestion of $\mathbf{H}$. G. Feichtinger we denote $B_{p, q}^{\mathfrak{a}}\left(\mathbf{R}_{n}\right)$ and $F_{p, q}^{\mathfrak{a}}\left(\mathbf{R}_{n}\right)$ as modulation spaces. The main aim of this paper is to study the trace problem: What can be said about the trace operator $R$,

$$
R: f(x) \rightarrow f\left(x^{\prime}, 0\right) \text {, where } x=\left(x^{\prime}, x_{n}\right),
$$

as a mapping from $B_{p, q}^{\mathfrak{a}}\left(\mathbf{R}_{n}\right)$ or $F_{p, q}^{\mathrm{a}}\left(\mathbf{R}_{n}\right)$ onto corresponding spaces on $\mathbf{R}_{n-1}$ ? Our main results are formulated in the Theorems 1 and 2, and in the Corollary. Furthermore, Theorem 3 contains a continuous version of (2) and (3). We give detailed proofs as far as the spaces $B_{p, q}^{a}\left(\mathbf{R}_{n}\right)$ are concerned and outline the proofs for the (technically more complicated but also more interesting) spaces $F_{p, q}^{\mathrm{a}}\left(\mathbf{R}_{n}\right)$. 
The interest on the above spaces comes from two quite different sources. H. G. Feichitinger introduced in [2] spaces of Wiener type on locally compact abelian groups, cf. also $[3,4]$. It comes out that $F B_{p, q}^{\mathrm{a}}\left(\mathbf{R}_{n}\right)$ (the Fourier image of $B_{p, q}^{\mathrm{a}}\left(\mathbf{R}_{n}\right)$ ) with $1 \leqq p, q \leqq \infty$ is a space of Wiener type on $\mathbf{R}_{n}$ in the sense of Feichtinger. So one can try to look at spaces of type $B_{p, q}^{\mathfrak{a}}$ with $1 \leqq p, q \leqq \infty$ on locally compact abelian groups in the framework of the technique used there, cf. [5]. Our approach is restricted to $\mathbf{R}_{n}$, but includes the spaces $F_{p, q}^{\mathrm{a}}\left(\mathbf{R}_{n}\right)$ and extends the range of $p, q$ to $0<p$, $q \leqq \infty\left(p<\infty\right.$ for $\left.F_{p, q}^{a}\left(\mathbf{R}_{n}\right)\right)$. The other source is the spaces $B_{p, q}^{s}\left(\mathbf{R}_{n}\right)$ and $F_{p, q}^{s}\left(\mathbf{R}_{n}\right)$, where again $0<p, q \leqq \infty$ and $-\infty<s<\infty$. These two scales include many wellknown spaces of functions and distributions, e.g. Hölder-Zygmund spaces, Sobolev spaces, Besov spaces, Bessel-potential spaces, Hardy spaces and BMO. Let

$$
\begin{aligned}
& Q_{k}=\left\{x\left|x=\left(x_{1}, \ldots, x_{n}\right) \in \mathbf{R}_{n}, \quad\right| x_{j} \mid \leqq 2^{k}\right\}, \\
& P_{k}=Q_{k+1}-Q_{k} \quad \text { if } k=1,2,3, \ldots \text { and } P_{0}=Q_{1} .
\end{aligned}
$$

The corridors $P_{k}$ with $k=1,2, \ldots$ can be divided in an obvious way in cubes with side-length $2^{k}$. One obtains a covering of $\mathbf{R}_{n}$ by "dyadic" cubes instead of a covering of $\mathbf{R}_{n}$ by congruent cubes, which underlies (2) and (3). Roughly speaking, the quasinorms of the spaces $B_{p, q}^{s}\left(\mathbf{R}_{n}\right)$ and $F_{p, q}^{s}\left(\mathbf{R}_{n}\right)$ are defined in the same way as in (2) and (3), respectively, where the covering of $\mathbf{R}_{n}$ by congruent cubes is replaced by the above dyadic covering and $a_{k}=2^{k s}$. The theory of the spaces $B_{p, q}^{s}\left(\mathbf{R}_{n}\right)$ and $F_{p, q}^{s}\left(\mathbf{R}_{n}\right)$ from the just-described standpoint has been developed in the three books $[13,15,16]$. It seems to be natural to ask whether the covering of $\mathbf{R}_{n}$ by dyadic cubes can be replaced by other coverings. The first question is for what coverings of $\mathbf{R}_{n}$ (or locally compact abelian groups etc.) definitions of type (2), (3) make sense. Considerations what coverings are admissible can be found in [14: Chapter 2] and [1,7], the latter one in locally compact spaces. The second question is whether one can characterize elements of corresponding $B$-spaces and/or $F$-spaces and their quasi-norms in other terms, e.g. via differences and derivatives of functions, approximation procedures or as traces of harmonic functions or temperatures (just as in the case of the spaces $B_{p, q}^{s}\left(\mathbf{R}_{n}\right)$ and $\left.F_{p, q}^{s}\left(\mathbf{R}_{n}\right)\right)$. Some work in this direction has been done. Beside [14: Chapter 2] we refer to the papers by M. L. Gol'Dman $[8,9]$, G. A. Kaldabin $[11,12]$ and $S$. . TANSON [10]. The feeling is that some regularity assumptions for the admissible coverings of $\mathbf{R}$, are necessary in order to get substantial results (cf. the papers by Kaljabin, Gol'dman and Janson). Probably the congruent covering is a limiting case for that purpose and of peculiar interest may be coverings which are "between" the congruent and the dyadic covering or coverings where the cubes (or more general, rectangles) grow even more rapid than in the dyadic case. In this sense this paper is also a contribution to the study of the limiting case. "congruent covering". In particular we wish to show what is different in comparison with the "dyadic covering".

As far as the above spaces $B_{p . q}^{a}\left(\mathbf{R}_{n}\right)$ with $1 \leqq p \leqq \infty$ (and $0<q \leqq \infty$ ) are concerned we refer to M. I. Gol'dman's paper [9]. His approach covers these spaces as a special case. Compare in particular Theorem 1 and the Corollary below with Theorem 7, remark 1 on p. 57, and Subsection 4.1 in [9].

Acknowledgement: The first draft of this paper has been written during a visit of the author in November 1981 in Vienna. I take the opportunity to thank my colleagues in Austria for their hospitality and Dr. H. G. Feichtinger and P. Gröbner from the University of Vienna for stimulating discussions about the subject of this paper. As an outgrowth we planned this paper and [5] (cf. also [6], which is a survey, including a description of further research). 


\section{Definitions and Preliminaries}

As in the Introduction, $\mathbf{R}_{n}$ stands, for the euclidean $n$-space and the lattice $\mathbf{Z}_{n}$ is given by (1). Let $S\left(\mathbf{R}_{n}\right)$ be the Schwart\% space of all complex-valued infinitely differentiable rapidly decreasing functions on $\mathbf{R}_{n}$. The Fourier transform and its inverse on $S\left(\mathbf{R}_{n}\right)$ are denoted by $F$ and $F^{-1}$, respectively. Let $S^{c}\left(\mathbf{R}_{n}\right)$ be the collection of all $f \in S\left(\mathbf{R}_{n}\right)$ such that $F f$ has a compact support. If $0<p<\infty$ then

$$
\left\|f \mid L_{p}\left(\mathbf{R}_{n}\right)\right\|=\left(\int_{\mathbf{R}_{n}}|f(x)|^{p} d x\right)^{1 / p}
$$

and $\left\|f\left|L_{\infty}\left(\mathbf{R}_{n}\right) \|=\sup _{x \in \mathbf{R}_{n}}\right| f(x) \mid\right.$. Finally, let $\left\{\varphi_{k}(x)\right\}_{k \in \mathbf{Z}_{n}}$ be essentially a smooth resolution of unity related to the lattice $\mathbf{Z}_{n}$, i.e. :

(i)

$$
\varphi_{k}(x) \in S\left(\mathbf{R}_{n}\right), \quad \operatorname{supp} \varphi_{k} \subset\left\{y\left|y=\left(y_{1}, \ldots, y_{n}\right) \in \mathbf{R}_{n}, \quad\right| y_{j}-k_{j} \mid \leqq 1\right\}
$$

where $k=\left(k_{1}, \ldots, k_{n}\right) \in \mathbf{Z}_{n}$,

(ii) for every multi-index $\gamma$ there exists a number $c_{y}$ such that

$$
\left|D^{y} \varphi_{k}(x)\right| \leqq c_{y} \text { for all } k \in \mathbf{Z}_{n},
$$

(iii) there exists a positive number $c$ such that

$$
\left.c \leqq \sum_{k \in Z_{n}} \varphi_{k}(x) \text { for all } x \in \mathbf{R}_{n} \cdot{ }^{1}\right)
$$

If $\sum_{k \in Z_{n}} \varphi_{k}(x) \equiv 1$ then we have a smooth resolution of unity: For technical reasons the bit more general version (4) is convenient for us. $\left\{\varphi_{k}(x)\right\}_{k \in Z_{n}}$ with (i) -(iii) we call ${ }^{*}$ admissible systems.

Definition 1 : Let $a=\left\{a_{k}\right\}_{k \in Z_{n}}$ be a sequence of positive numbers with

$$
\begin{aligned}
& 0<c_{1} \leqq \frac{a_{k}}{a_{\tilde{k}}} \leqq c_{2}<\infty \quad \text { for all } k \in \mathbf{Z}_{n} \text { and } \tilde{k} \in \mathbf{Z}_{n} \\
& \text { with }|k-\tilde{k}|=1
\end{aligned}
$$

where $c_{1}$ and $c_{2}$ are two suitable positive numbers. Tet $\varphi=\left\{\varphi_{k}(x)\right\}_{k \in Z_{n}}$ be an admissible system in the above sense.

(i) Let $0<p \leqq \infty$ and $0<q \leqq \infty$. Then $S^{\mathrm{c}}\left(\mathbf{R}_{n}\right)$ equipped with the quasi-norm

$$
\left\|f \mid B_{p_{. q}}^{\mathrm{a}}\left(\mathbf{R}_{n}\right)\right\|^{\varphi}=\left(\sum_{k \in Z_{n}} a_{k}^{q} \| F^{-1}\left[\varphi_{k} F f\right] \mid L_{p}\left(\mathbf{R}_{n} \|^{q}\right)^{1 / q}\right.
$$

is denoted as $B_{p, q}^{\mathfrak{a}}\left(\mathbf{R}_{n}\right)$ (usual modification if $q=\infty$ ).

(ii) Let $0<p<\infty$ and $0<q \leqq \infty$. Then $S^{\mathrm{c}}\left(\mathbf{R}_{n}\right)$ equipped with the quasi-norm

$$
\left\|f\left|F_{p, q}^{\mathrm{a}}\left(\mathbf{R}_{n}\right)\left\|^{\Phi}=\right\|\left(\sum_{k \in \mathbb{Z}_{n}} a_{k}^{q}\left|F^{-1}\left[\varphi_{k} F f\right](\cdot)\right|^{q}\right)^{1 / q}\right| L_{p}\left(\mathbf{R}_{n}\right)\right\|
$$

is denoted as $F_{p . q}^{\mathfrak{a}}\left(\mathbf{R}_{n}\right)$ (usual modification if $q=\infty$ ).

Remark 1: For sake of brevity we write $F^{-1} \varphi_{k} F f$ instead of $F^{-1}\left[\varphi_{k} F f\right]$ in the sequel. Of course, (6) and (7) make sense. In particular, by the Paley-Wiener-theorem, $F^{-1} \varphi_{k} F f$ is an analytic function (belonging to $S\left(\mathbf{R}_{n}\right)$ ). Of course, $(6)$ and $(7)$ are quasinorms (norms if $p \geqq 1$ and $q \geqq 1$ ). We recall that a quasi-norm $\|\cdot\|$ has all the prop-

1) All unimportant positivo numbers are denoted by $c, c_{1}, \ldots, \dot{c}^{\prime}, \ldots$ where the numerical values of these numbers may differ from formula to formula. 
erties of a norm, only the triangle inequality is replaced by

$$
\left\|h_{1}+h_{2}\right\| \leqq c\left(\left\|h_{1}\right\|+\left\|h_{2}\right\|\right),
$$

where $c \geqq 1$ is independent of $h_{1}$ and $h_{2}$.

Remark 2: For sake of simplicity we restrict our considerations to $S^{c}\left(\mathbf{R}_{n}\right)$. The idea is to extend the definitions of $B_{p, q}^{a}\left(\mathbf{R}_{n}\right)$ and $F_{p . q}^{a}\left(\mathbf{R}_{n}\right)$ to suitable distributions from $S^{\prime}\left(\mathbf{R}_{n}\right)$ or from other appropriate spaces of distributions. (From that point of view it would be better to denote $S^{c}\left(\mathbf{R}_{n}\right)$ equipped with $(6)$ by $\hat{B}_{p, q}^{\mathfrak{a}}\left(\mathbf{R}_{n}\right)$, etc.) To find suitable distribution spaces for an extended definition of $B_{p, q}^{a}\left(\mathbf{l}_{n}\right)$ and $F_{p, q}^{a}\left(\mathbf{R}_{n}\right)$ is a somewhat delicate question. A detailed discussion may be found in [9], cf. also [14: 2.2.3]. However it is quite clear that the assertions of this paper can be extended via limiting processes to extended spaces of type $B_{p, q}^{\mathfrak{a}}\left(\mathbf{R}_{n}\right)$ and $F_{p, q}^{\mathfrak{a}}\left(\mathbf{R}_{n}\right)$.

Remark 3: As has been said in the introduction the dyadic counterpart of $B_{p . q}^{\text {a }}\left(\mathbf{R}_{n}\right)$ and $F_{p, q}^{\mathrm{a}}\left(\mathbf{R}_{n}\right)$ are the spaces $B_{p, q}^{s}\left(\mathbf{R}_{n}\right)$ and $F_{p, q}^{s}\left(\mathbf{R}_{n}\right)$, respectively, $-\infty<s<\infty$. For these spaces we have an elaborated theory at hand, cf. $[15,16]$. Some parts of that theory are independent of the underlying covering of $\mathbf{R}_{n}$ if it is regular enough (e.g. congruent or dyadic coverings). In particular, for given $p$ 's and $q$ 's the quasi-norms (6) for all admissible systems $\varphi$ are pairwise equivalent (i.e. for two admissible systems $\varphi$ the quotients of the corresponding quasi-norns (6) can be estimated from above and from below by positive constants, which are independent of the elements of $S^{c}\left(\mathbf{R}_{n}\right)$ ). Similarly for the quasi-norms (7). In this sense we write $\left\|f \mid B_{p, q}^{\mathrm{a}}\left(\mathbf{R}_{n}\right)\right\|$ and $\left\|f \mid F_{p, q}^{\mathrm{a}}\left(\mathbf{R}_{n}\right)\right\|$ instead of $\left\|f \mid B_{p, q}^{\mathrm{a}}\left(\mathbf{R}_{n}\right)\right\|^{\varphi}$ and $\left\|f \mid F_{p, q}^{\mathrm{a}}\left(\mathbf{R}_{n}\right)\right\|^{\varphi}$, respectively, in the sequel. Furthermore, it is no problem to prove Fourier multiplier theorems and maximal inequalities for the spaces $B_{p, q}^{a}\left(\mathbf{R}_{n}\right)$ and $F_{p, q}^{a}\left(\mathbf{R}_{n}\right)$ in the same way as this has been done in [16] for the spaces $B_{p, q}^{s}\left(\mathbf{R}_{n}\right)$ and $F_{p, q}^{s}\left(\mathbf{R}_{n}\right)$ (cf. the Proposition below). Other properties are different, e.g. the traces on hyperplanes, which is the subject of this paper.

Definition 2 (Maximulfunctions): Let $b>0, d>0$ and $f \in S\left(\mathbf{R}_{n}\right)$. Let $\left\{\varphi_{k}(x)\right\}_{k \in Z_{n}}$ be an admissible system in the above sense. Then

and

$$
\left(\varphi_{k} f\right)^{*}(x)=\sup _{\boldsymbol{y} \in \mathbf{R}_{n}} \frac{\left|\left(F^{-1} \varphi_{k} F f\right)(x-y)\right|}{1+|y|^{b}}, \quad x \in \mathbf{R}_{n}, \quad k \in \mathbf{Z}_{n}
$$

$$
\left(\varphi_{k} f\right)_{n}^{*}(x)=\sup _{i \in \mathbf{R}_{1}} \frac{\left|\left(F^{-1} \varphi_{k} F f\right)\left(x^{\prime}, x_{n}-t\right)\right|}{1+|t|^{d}}, \quad x=\left(x^{\prime}, x_{n}\right) \in \mathbf{R}_{n}, \quad k \in \mathbf{Z}_{n} .
$$

Remark 4: We have

$$
\left(\varphi_{k} f\right)^{*}(x) \geqq\left(\varphi_{k} f\right)_{n}^{*}(x) \geqq\left|\left(F^{-1} \varphi_{k} F f\right)(x)\right|, \quad x \in \mathbf{R}_{n} .
$$

Of course, $\left(\varphi_{k} f\right)^{*}(x)$ and $\left(\varphi_{k} f\right)_{n}{ }^{*}(x)$ depend on $b$ and $d$, respectively. However this is urimportant (under the restrictions formulated below). So we omit $b$ and $d$ as indices. Of course, (8) and (9) make also sense if (4) is not satisfied. Proposition: (i) Let $0<p \leqq \infty$ and $0<q \leqq \infty$. Let $b>\frac{n}{p}$ in (8) and $d>\frac{1}{p}$
in (9). Then

and

$$
\left.\begin{array}{l}
\left(\sum_{k \in \mathbf{Z}_{n}} a_{k}^{q}\left\|\left(\varphi_{k} f\right)^{*} \mid L_{p}\left(\mathbf{R}_{n}\right)\right\|^{q}\right)^{1 / q} \\
\left(\sum_{k \in Z_{n}} a_{k}^{q}\left\|\left(\varphi_{k} f\right)_{n}^{*} \mid L_{p}\left(\mathbf{R}_{n}\right)\right\|^{q}\right)^{1 / q}
\end{array}\right\} .
$$


are equivalent quasi-norms in $B_{p . q}^{\mathrm{a}}\left(\mathbf{R}_{n}\right)$ (modification if $\left.q=\infty\right)$. If (4) is not ensured then the expressions from (11) can be estimated from above by the quasi-norm in $B_{p, q}^{\mathrm{a}}\left(\mathbf{R}_{n}\right)$.

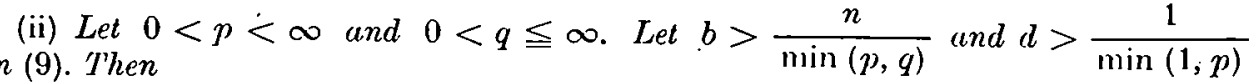

and

$$
\left.\begin{array}{l}
\left\|\left(\sum_{k \in Z_{n}} a_{k}^{q} \cdot\left|\left(\varphi_{k} f\right)^{*}(\cdot)\right|^{q}\right)^{1 / q} \mid L_{p}\left(\dot{\mathbf{R}}_{n}\right)\right\| \\
\left\|\left(\sum_{k \in Z_{n}} a_{k}^{q}\left|\left(\varphi_{k} f\right)_{n}^{*}(\cdot)\right|^{q}\right)^{1 / q} \mid L_{p}\left(\mathbf{R}_{n}\right)\right\|
\end{array}\right\}
$$

are equivalent quasi-norms in $F_{p, q}^{a}\left(\mathbf{R}_{n}\right)$ (modification if $q=\infty$ ). If (4) is not ensured then the expressions from (12) cun be estimated from above by the quasi-norm in $F_{p, q}^{a}\left(\mathbf{R}_{n}\right)$.

Remark 5: The Proposition is an easy consequence of Theorem 1.4.1 and Theorem 1.6.2 in [16]. It is the counterpart of corresponding maximal inequalities for the spaces $B_{p, q}^{s}\left(\mathbf{R}_{n}\right)$ and $F_{p, q}^{s}\left(\mathbf{R}_{n}\right)$ in $[15,16]$.

\section{Traces of $B_{p, q}^{a}\left(R_{n}\right)$}

\subsection{Main Assertion}

The trace operator $R$ is given by

$$
R f=f\left(x^{\prime}, 0\right) \text {, where } f(x) \in S^{c}\left(\mathbf{R}_{n}\right) \text { and } x=\left(x^{\prime}, x_{n}\right), x^{\prime} \in \mathbf{R}_{n-1} .
$$

Our aim is to find a space $B_{p . q}^{a^{\prime}}\left(\mathbf{R}_{n-1}\right)$ with a suitable sequence $\mathfrak{a}^{\prime}=\left\{a_{k}{ }^{\prime}\right\}_{k^{\prime} \in \mathbf{Z}_{n-1}}{ }^{\cdots}$ of positive numbers such that $R$ is a linear and bounded operator from the given space $B_{p, q}^{a}\left(\mathbf{R}_{n}\right)$ onto $B_{p, q}^{a^{\prime}}\left(\mathbf{R}_{n-1}\right)$. Furthermore, $R$ is called a retraction if there exists a linear and bounded operator $T$ from $B_{p, q}^{a^{\prime}}\left(\mathbf{R}_{n-1}\right)$ into $B_{p, q}^{\mathfrak{a}}\left(\mathbf{R}_{n}\right)$ such that

$$
\left.R^{\prime} T^{\prime}=I \quad \text { (identity in } B_{p, q}^{a^{\prime}}\left(R_{n-1}\right)\right) \text {. }
$$

(In that case it is clear that $R$ maps "onto".) We call $T$ a coretraction (to the retraction $R$ ) or an extension operator.

Theorem 1: Let $0<p \leqq \infty, \bar{p}=\min (1, p)$ and $0<q \leqq \infty$. Let $a=\left\{a_{k}\right\}_{k \in Z_{n}}$ be a sequence of positive numbers with (5). If $k \in \mathbf{Z}_{n}$ then we put $k=\left(k^{\prime}, k_{n}\right)$ with $k^{\prime} \in \mathbf{Z}_{n-1}$ und $k_{n} \in \mathbf{Z}_{1}$. Let $k^{\prime} \in \mathbf{Z}_{n-1}$,

and

$$
a_{k^{\prime}}^{\prime}=\inf _{l \in \mathbf{Z}_{1}} a_{\left(k^{\prime}, l\right)}>0 \text { if } \quad 0<q \leqq \bar{p}
$$

$$
a_{k^{\prime}}^{\prime \sigma}=\sum_{l=-\infty}^{\infty} a_{\left(k^{\prime}, l\right)}^{-\sigma}<\infty \text { with } \frac{1}{\sigma}=\frac{1}{\bar{p}}-\frac{1}{q} \text { if } \bar{p}<q \leqq \infty .
$$

T'hen $B_{p, Q}^{\mathfrak{a}^{\prime}}\left(\mathbf{R}_{n-1}\right)$ is a space in the sense of Definition 1 (i). If there exists a positive number $A$ such that $a_{k^{\prime}} \geqq A a_{\left(k^{\prime}, 0\right)}$ for all $k^{\prime} \in \mathbf{Z}_{n-1}$, then $R$ is a retraction from $B_{p, q}^{\mathfrak{a}}\left(\mathbf{R}_{n}\right)$ onto $B_{p . q}^{a^{\prime}}\left(\mathbf{R}_{n-1}\right)$. Furthermore, there exists a corresponding coretruction ' $I$ ' in the sense of (14), which is independent of $\mathfrak{a}, p$ and $q$.

Proof: Step 1. It is easy to see that the sequence $\mathfrak{a}^{\prime}=\left\{a_{k^{\prime}}^{\prime}\right\}_{k^{\prime} \in Z_{n-1}}$ satisfies (5) with $n-1$ instead of $n$. Hence, $B_{p, q}^{n^{\prime}}\left(\mathbf{R}_{n-1}\right)$ is a space in the sense of Definition 1 (i). 
Step 2. Notations with respect to $\mathbf{R}_{n-1}=\left\{y \mid y \in \mathbf{R}_{n}, y=\left(y^{\prime}, 0\right)\right\}$ are indicated by '. In particular, $F^{\prime}$ and $F^{\prime-1}$ are the Fourier transform and its inverse on $S\left(\mathbf{R}_{n-1}\right)$. If $f(x) \in S^{c}\left(\mathbf{R}_{n}\right)$ then $f\left(x^{\prime}, 0\right) \in S^{c}\left(\mathbf{R}_{n-1}\right)$. Let $\varphi^{\prime}=\left\{\varphi_{k}^{\prime}\left(x^{\prime}\right)\right\}_{k^{\prime} \in \mathbf{Z}_{n-1}}$ be an admissible system in the above sense (with respect to $\mathbf{R}_{n-1}$ ). We have to calculate

$$
\left\{F^{\prime-1} \varphi_{k}^{\prime} F^{\prime}\left(f\left(x^{\prime}, 0\right)\right)\right\}\left(y^{\prime}\right)=\sum_{l \in Z_{n}}\left\{F^{\prime-1} \varphi_{k^{\prime}}^{\prime} F^{\prime}\left[\left(F^{-1} \varphi_{l} F f\right)\left(x^{\prime}, 0\right)\right]\right\}\left(y^{\prime}\right)
$$

with $y^{\prime} \in \mathbf{R}_{n-1}$. By elementary arguments we have

$$
\left\{F^{\prime-1} \varphi_{k}^{\prime} \cdot F^{\prime}\left[\left(F^{\prime-1} \varphi_{l} F f\right)\left(x^{\prime}, 0\right)\right]\right\}\left(y^{\prime}\right)=\left(F^{-1} \varphi_{k^{\prime}}^{\prime} \varphi_{l} F f\right)\left(y^{\prime}, 0\right),
$$

where the left-hand side is considered as a function in $\mathbf{R}_{n-1}$ and the right-hand side as a function in $\mathbf{R}_{n}$. Obviously, $\varphi_{k^{\prime}}^{\prime}\left(x^{\prime}\right) \varphi_{l}\left(x^{\prime}, x_{n}\right)=0$ if $k^{\prime}=\left(k_{1}, \ldots, k_{n-1}\right), l=\left(l_{1}, \ldots, l_{n}\right)$ and $\max \left|k_{t}-l_{t}\right|>1$. Consequently

$$
F^{\prime-1} P_{k^{\prime}}^{\prime} F^{\prime}(f(\cdot, 0))\left(x^{\prime}\right)=\sum_{m=-\infty}^{\infty}\left(F^{-1} \varphi_{k^{\prime}}^{\prime} \varphi_{\left(k^{\prime}, m\right)} F f\right)\left(x^{\prime}, 0\right)+\cdots=h_{k^{\prime}}\left(x^{\prime}\right)+\cdots
$$

where $+\cdots$ indicates sums of the above type where $\varphi_{\left(k^{\prime}, m\right)}$ must be replaced by $\varphi_{(l, m)}$ with $\max \left|k_{t}-l_{l}\right|=1$. Of course, $l^{\prime}=\left(l_{1}, \ldots, l_{n-1}\right)$. It will be sufficient to deal only with $h_{k^{\prime}}\left(x^{\prime}\right)$ in the sequel. The above Proposition can be applied to $\left\{\psi_{k}(x)\right\}_{k \in Z_{n}}$ with $\psi_{k}(x)=\varphi_{k^{\prime}}^{\prime}\left(x^{\prime}\right) \varphi_{\left(k^{\prime}, k_{n}\right)}(x)$ where $x \in \mathbf{R}_{n}$ and $k=\left(k^{\prime}, k_{n}\right)$. If $1 \leqq x_{n} \leqq 2$ then we have

$$
\left|\left(F^{-1} \psi_{k} F f\right)\left(x^{\prime}, 0\right)\right|^{p} \leqq c\left(\psi_{k} f\right)_{n}^{* p}(x) \text { where } x \in\left(x^{\prime}, x_{n}\right) \text {. }
$$

We put (18) in (17). Let $0<p \leqq 1$. Afterwards we apply the inequality

$$
\left(\sum_{j} \alpha_{j}\right)^{p} \leqq \sum_{j} \alpha_{j}^{p} \quad \text { if } \quad \alpha_{i} \geqq 0
$$

and integrate over $\mathbf{R}_{n-1} \times[1,2]$. Then we have

$$
\left\|h_{k^{\prime}}(\cdot)\left|L_{p}\left(\mathbf{R}_{n-1}\right)\left\|^{p} \leqq c \sum_{m=-\infty}^{\infty}\right\|\left(\psi_{\left(k^{\prime}, m\right)} f\right)_{n}^{*}(\cdot)\right| L_{p}\left(\mathbf{R}_{n}\right)\right\|^{p}, \quad 0<p \leqq 1 .
$$

Jf $1 \leqq p \leqq \infty$. then we use the triangle inequality instead of (19) and obtain that

$$
\left\|h_{k^{\prime}}(\cdot)\left|L_{p}\left(\mathbf{R}_{n-1}\right)\left\|\leqq c \sum_{m=-\infty}^{\infty}\right\|\left(\psi_{\left(k^{\prime}, m\right)} f\right)_{n}^{*}(\cdot)\right| L_{p}\left(\mathbf{R}_{n}\right)\right\|, \quad \cdot 1 \leqq p \leqq \infty
$$

let $0<q \leqq p \leqq 1$, in particular we have $\bar{p}=p$. Then (15) and (20) yield

$$
\begin{aligned}
& \sum_{k^{\prime} \in Z_{n-1}} a_{k^{\prime}}^{q q}\left\|h_{k^{\prime}} \mid L_{p}\left(\mathbf{R}_{n-1}\right)\right\|^{q} \\
& \leqq c \sum_{m=-\infty}^{\infty} \sum_{k^{\prime} \in \mathbf{Z}_{n-1}} a_{k^{\prime}}^{q}\left\|\left(\psi_{\left(k^{\prime}, m\right)} f\right)_{n}{ }^{*}\left|L_{p}\left(\mathbf{R}_{n}\right)\left\|^{q} \leqq c \sum_{l \in \mathbf{Z}_{n}} a_{l}^{q}\right\|\left(\psi_{l} f\right)_{n}{ }^{*}\right| L_{p}\left(\mathbf{R}_{n}\right)\right\|^{q} .
\end{aligned}
$$

We have similar estimates for the terms indicated in (17) by $+\cdots$. Now it follows from (17), (22) and the Proposition that

$$
\left\|f(\cdot, 0)\left|B_{p, q}^{\mathfrak{a}^{\prime}}\left(\mathbf{R}_{n-1}\right)\|\leqq c\| f\right| B_{p, q}^{\mathfrak{a}}\left(\mathbf{R}_{n}\right)\right\| .
$$

Hence, $R$ is a bounded operator from $\ddot{B}_{p, q}^{\mathrm{a}}\left(\mathbf{R}_{n}\right)$ into $B_{p q}^{a^{\prime}}\left(\mathbf{R}_{n-1}\right)$. Let $0<p \leqq 1$ and $p<q \leqq \infty$. Again we have $p=\bar{p}$. Then we apply Hölder's inequality with respect to 
$\frac{p}{q}+\frac{p}{\sigma}=1$ to $(20)$ and obtain that

$$
\begin{aligned}
& \left\|h_{k^{\prime}}(\cdot) \mid L_{p}\left(\mathbf{R}_{n-1}\right)\right\|^{p} \\
& \leqq c\left(\sum_{m=-\infty}^{\infty} a_{\left(k^{\prime}, m\right)}^{-q}\right)^{p / \sigma}\left(\sum_{m=-\infty}^{\infty} a_{\left(k^{\prime}, m\right)}^{q}\left\|\left(\psi_{\left(k^{\prime}, m\right)} f\right)_{n} *(\cdot) \mid L_{p}\left(\mathbf{R}_{n}\right)\right\|^{q}\right)^{p / q} .
\end{aligned}
$$

We use (16), take the $\frac{q}{p}$-power of (24), sum over $k^{\prime} \in \mathbf{Z}_{n-1}$ and apply again (17) and the Proposition. The result is (23). The case $1 \leqq p \leqq \infty$ follows the same line where one has to replace (20) by (21). Hence, (23) holds in all cases under consideration.

Step 3. We construct an extension operator $T$ from $B_{p, q}^{\mathfrak{a}^{\prime}}\left(\mathbf{R}_{n-1}\right)$ into $B_{p, q}^{\mathfrak{a}}\left(\mathbf{R}_{n}\right)$ which satisfies (14). Let $\chi(t) \in S\left(\mathbf{R}_{1}\right)$ be a function with

$$
\operatorname{supp} \chi \subset\left(-\frac{1}{4}, \frac{1}{4}\right) \text { and }\left(F_{1}^{-1} \chi\right)(0)=1,
$$

where $F_{1}^{-1}$ is the inverse one-dimensional Fourier transform. Iet $g\left(x^{\prime}\right) \in B_{p . q}^{\mathrm{a}^{\prime}}\left(\mathbf{R}_{n-1}\right)$. We use the above notations and put

$$
f(x)=\left(T^{\prime} g\right)(x)=\sum_{k^{\prime} \in Z_{n-1}}\left(F_{1}^{-1} \not\right)\left(x_{n}\right)\left(F^{\prime-1} \varphi_{k}^{\prime} F^{\prime} g\right)\left(x^{\prime}\right), \quad x=\left(x^{\prime}, x_{n}\right) .
$$

Of course, $T$ is linear. Let $\sum_{k^{\prime} \in \mathbf{Z}_{n-1}} \varphi_{k^{\prime}}^{\prime}\left(x^{\prime}\right) \equiv 1$ in $\mathbf{R}_{n-1}$. Then we have $f\left(x^{\prime}, 0\right)=g$, i.e. (14) holds. I tet $\left\{\varphi_{k}(x)\right\}_{k \in \mathbf{Z}_{n}}$ be an admissible system in $\mathbf{R}_{n}$, where we may assume that

$$
\varphi_{k}(x)=\varphi_{k^{\prime}}^{\prime}\left(x^{\prime}\right) \varrho_{k_{n}}\left(x_{n}\right), \quad k=\left(k^{\prime}, k_{n}\right), \quad x=\left(x^{\prime}, x_{n}\right),
$$

with appropriate functions $\varrho_{m}\left(x_{n}\right), m \in \mathbf{Z}_{1}$. We may assume that $\varrho_{m}(\ell) \chi(t)=0$ if $m \neq 0$. We have

$$
\left(F^{-1} \varphi_{k} F f\right)(x)=\left(F_{1}^{-1} \varrho_{k_{n}} \chi\right)\left(x_{n}\right)\left(F^{\prime-1} \varphi_{k^{\prime}}^{\prime 2} F^{\prime} g\right)\left(x^{\prime}\right)+\cdots
$$

where $+\cdots$ must be understood similarly as in (17). Again we can restrict our attention to the first term on the right-hand side of (27). If $k_{n} \neq 0$ then $\left(F^{-1} \varphi_{k} F f\right)(x)=0$ by our assumption. Then it follows that

$$
\begin{aligned}
& \sum_{m=-\infty}^{\infty} a_{\left(k^{\prime}, m\right)}^{q}\left\|F^{-1} \varphi_{\left(k^{\prime}, m\right)} F / \mid L_{p}\left(\mathbf{R}_{n}\right)\right\|^{q} \\
& \leqq c a_{\left(k^{\prime}, 0\right)}^{q}\left\|F^{\prime-1} \varphi_{k^{\prime}}^{\prime 2} F^{\prime} g \mid L_{p}\left(\mathbf{R}_{n-1}\right)\right\|^{q}+\cdots
\end{aligned}
$$

(modification if $q=\infty$ ). By our hypotheses we have $a_{\left(k^{\prime}, 0\right)} \leqq A^{-1} a_{k^{\prime}}^{\prime}$. Hence, (28) can be estimated from above by

$$
c a_{k^{\prime}}^{\prime q}\left\|F^{\prime-1} \varphi_{k^{\prime}}^{\prime 2} F^{\prime} g \mid L_{p}\left(\mathbf{R}_{n-1}\right)\right\|^{q}+\cdots
$$

We sum over $k^{\prime} \in Z_{n-1}$ and apply the Proposition. We obtain that

$$
\left\|T g\left|B_{p, q}^{\mathfrak{a}}\left(\mathbf{R}_{n}\right)\|\leqq c\| g\right| B_{p, q}^{\mathfrak{a}^{\prime}}\left(\mathbf{R}_{n-1}\right)\right\|
$$

for all admissible $p$ 's, $q$ 's and a's. The proof is complete.

Remark 6: The operator $T$ from (26) is independent of $a, p$ and $q$. This has some advantages, in particular if one wishes to apply interpolation methods, where couples of different spaces of type $B_{p, q}^{\mathfrak{a}}\left(\mathbf{R}_{n}\right)$ and $F_{p, q}^{\mathfrak{a}}\left(\mathbf{R}_{n}\right)$ come in. This will be done in Sub- 
section 4.2. 'The price for the independence of ' $T$ ' on $\mathfrak{a}, p, q$ is paid by the aditional assumption $a_{k^{\prime}}^{\prime} \geqq A a_{\left(k^{\prime}, 0\right)}$. In the next subsection we shall show that this assumption can be omitted (at least for some $p$ and $q$ ), but the extension operator $T$ depends on the sequence $\mathfrak{a}$ (and hence is not useful for interpolation purposes).

\subsection{Modifications}

It is our aim to remove the condition $a_{k^{\prime}}^{\prime} \geqq A a_{\left(k^{\prime}, 0\right)}$ from Theorem 1 .

Corollary: Let $0<p \leqq \infty, \bar{p}=\min (1, p)$, and $0<q \leqq \infty$. Let $\left\{a_{k}\right\}_{k \in Z_{n}}$ be $a$ sequence of positive numbers with (5). Let $a^{\prime}=\left\{a_{k^{\prime}}\right\}_{k^{\prime} \in \mathrm{Z}_{n-1}}$ be given by (15) and (16), respectively. If

$$
\left.\begin{array}{ll}
\text { either } & 0<q \leqq \bar{p} \\
\text { or } & 1 \leqq p<q \leqq \infty
\end{array}\right\}
$$

then $R$ is a retraction from $B_{p, q}^{\mathrm{a}}\left(\mathbf{R}_{n}\right)$ onto $B_{p, q}^{a^{\prime}}\left(\mathbf{R}_{n-1}\right)$.

Proof: We used the additional assumption $a_{k^{\prime}}^{\prime} \geqq A a_{\left(k^{\prime}, 0\right)}$ from Theorem 1 only in Step 3 of the proof of this theorem. In other words, only the construction of the extension operator $T$ ' from (26) must be modified. Let $0<q \leqq \bar{p}$. If $k^{\prime} \in \mathbf{Z}_{n-1}$ then we choose $l=l\left(k^{\prime}\right) \in \mathbf{Z}_{1}$ such that $a_{k^{\prime}}^{\prime} \geqq \frac{1}{2} a_{\left(k^{\prime}, l\right)}$. If $\chi$ is given by (25) then we put $\varkappa_{l}(t)=\chi(t-l)$. We modify $(26)$ by

$$
f(x)=\left(T^{\prime} g\right)(x)=\sum_{k^{\prime} \in Z_{n-1}}\left(F_{1}^{-1} \chi\left(k^{\prime}\right)\left(x_{n}\right)\left(F^{\prime-1} \varphi_{k^{\prime}}^{\prime} F^{\prime} g\right)\left(x^{\prime}\right), \quad x=\left(x^{\prime}, x_{n}\right) .\right.
$$

Again we have $f\left(x^{\prime}, 0\right)=g\left(x^{\prime}\right)$. The modified estimate $(28)$ with $a_{\left(k^{\prime}, l\right)}$ instead of $u_{\left(k^{\prime}, 0\right)}$ and the arguments afterwards show that $T$ ' has the desired properties. Let $1 \leqq p<q \leqq \infty$. Then $\bar{p}=1$. If $k^{\prime} \in \mathbf{Z}_{n-1}$ then we choose a natural number $N\left(k^{\prime}\right)$ and a number $C\left(k^{\prime}\right)$ with $1<C\left(k^{\prime}\right)<2$ such that

$$
C\left(k^{\prime}\right) \sum_{m \leqq N^{\prime}\left(k^{\prime}\right)} \frac{a_{k^{\prime}}^{\prime \sigma}}{a_{\left(k^{\prime}, l\right)}^{o}}=1
$$

cf. (16). Jet

$$
f(x)=\left(T^{\prime} g\right)(x)=\sum_{k^{\prime} \in Z_{n-1}} C\left(k^{\prime}\right) \sum_{|l| \leqq} \sum_{N^{\prime}\left(k^{\prime}\right)} \frac{a_{k^{\prime}}^{\prime \sigma}}{a_{\left(k^{\prime}, l\right)}^{\sigma}}\left(F_{1}^{-1} \not l\right)\left(x_{n}\right)\left(F^{\prime-1} \varphi_{k^{\prime}}^{\prime} F^{\prime} g\right)(x)^{\prime},
$$

$x=\left(x^{\prime}, x_{n}\right)$. We have $f\left(x^{\prime}, 0\right)=g\left(x^{\prime}\right)$. We use (27). Then the counterpart of $(28)$ reads as follows,

$$
\begin{aligned}
& \sum_{m=-\infty}^{\infty} u_{\left(k^{\prime}, m\right)}^{q}\left\|F^{\prime-1} \varphi_{\left(k^{\prime}, m\right)} F f \mid L_{p}\left(\mathbf{R}_{n}\right)\right\|^{q} \\
& \leqq c u_{k^{\prime}}^{\prime \sigma q}\left\|F^{\prime-1} \varphi_{k^{\prime}}^{\prime 2} F^{\prime} g \mid L_{p}\left(\mathbf{R}_{n-1}\right)\right\|_{m=-\infty}^{q} \sum_{m=-\infty}^{\infty} a_{\left(k^{\prime}, m\right)}^{q(1-o)}+\cdots
\end{aligned}
$$

(modification if $q=\infty)$. We have $\frac{1}{\sigma}+\frac{1}{q}=1$ and consequently $q(1-\sigma)=-\sigma$ and $\sigma(q-1)=q$. Then it follows that

$$
\sum_{m=-\infty}^{\infty} a_{\left(k^{\prime}, m\right)}^{q}\left\|F^{-1} \varphi_{\left(k^{\prime}, m\right)} F^{\prime} f\left|L_{p}\left(\mathbf{R}_{n}\right)\left\|^{q} \leqq c a_{k^{\prime}}^{q}\right\| F^{\prime-1} \varphi_{k^{\prime}}^{\prime 2} F^{\prime} g\right| L_{p}\left(\mathbf{R}_{n-1}\right)\right\|^{q}+\cdots
$$

which yields the desired result by the above arguments. 
Remark 7: In contrast to (26), the operator $T$ from (32) and (34) depends on the sequence $\mathfrak{a}=\left\{a_{k}\right\}_{k \in Z_{n}}$. Of course, (31) does not cover all cases. What remains is the case $0<p<1, p<q$. Probably the Corollary remains valid also in this case. One must modify (34) (replacement of $F_{1}^{-1} \chi_{l}$ by more sophisticated functions). However we we have not checked this proposal in detail.

\section{Traces of $F_{p, q}^{\mathrm{a}}\left(\mathbf{R}_{n}\right)$}

\subsection{Main Assertion}

All notations have the same neaning as in Subsection 3.1 .

Theoreni 2: Let $0<p<\infty$ and $0<q \leqq \infty$. Let $\mathfrak{a}=\left\{a_{k}\right\}_{k \in \boldsymbol{Z}_{n}}$ be a sequence of positive numbers with (5). If $k \in \mathbf{Z}_{n}$ then we put $k=\left(k^{\prime}, k_{n}\right)$ with $k^{\prime} \in \mathbf{Z}_{n-1}$ and $k_{n} \in \mathbf{Z}_{1}$. By assumption there exists a positive number $c$ such that

$$
a_{\left(k^{\prime}, m\right)} \geqq c|m|^{*} \cdot a_{\left(k^{\prime}, 0\right)} \quad \text { with } \varkappa>\max \left(1, \frac{1}{p}, \frac{1}{q}\right)
$$

holds for all $k^{\prime} \in \mathbf{Z}_{n-1}$ and $m \in Z_{1}$. Then $F_{p, q}^{\mathfrak{a}^{\prime}}\left(\mathbf{R}_{n-1}\right)$ with

$$
\mathfrak{a}^{\prime}=\left\{a_{k^{\prime}}^{\prime}=a_{\left(k^{\prime} .0\right)}\right\}_{k^{\prime} \in Z_{n-1}}
$$

is a space in the sense of Definition 1 (ii) and $R$ is a retruction from $F_{p . q}^{a}\left(\mathbf{R}_{n}\right)$ onto $F_{p, q}^{a^{\prime}}\left(\mathbf{R}_{n-1}\right)$. Furthermore,'T' from (26) is a corresponding coretruction.

Proof (Outline): Step 1. It is easy to see that $F_{p, q}^{a^{\prime}}\left(\mathbf{R}_{n-1}\right)$ is a space in the sense of Definition 1 (ii). Furthermore, it follows from the arguments in Step 3 of the proof of Theorem 1 that ' $T$ ' from (26) is an extension operator with the desired properties.

Step 2. We must prove that $R$ is a bounded mapping from $F_{p, q}^{a}\left(\mathbf{R}_{n}\right)$ into $F_{p, q}^{a^{\prime}}\left(\mathbf{R}_{n-1}\right)$. Let $1=b_{0}<b_{1}<b_{2}<b_{3}<\cdots$. We beginn in the same way as in Step 2 of the proof of Theorem 1. Instead of (18) we use

$$
\left|\left(F^{-1} \psi_{k} F f\right)\left(x^{\prime}, 0\right)\right|^{2} \leqq c b_{m+1}^{d \lambda}\left(\psi_{k} f\right)_{n}^{* i}(x),
$$

where $x=\left(x^{\prime}, x_{n}\right), b_{m} \leqq x_{n} \leqq b_{m+1}, k=\left(k^{\prime}, m\right)$ with $m \geqq 0$ and $\lambda>0$. Here $d$ has the meaning of (9). Integration yiclds

$$
\left|\left(F^{-1} \psi_{k} F f\right)\left(x^{\prime}, 0\right)\right|^{\lambda} \leqq c b_{m+1}^{d \lambda}\left(b_{m+1}-b_{m}\right)^{-1} \int_{b_{m}}^{b_{m+2}}\left(\psi_{k} f\right)_{n}^{* \lambda}\left(x^{\prime}, x_{n}\right) d x_{n}
$$

with $k=\left(k^{\prime}, m\right), m \geqq 0$. A sinilar formula holds if $m<0$. Let $0<\lambda \cdot<\min (p, q)$. Let e.g. $0<q \leqq 1$. We use the abbreviation $h_{k^{\prime}}\left(x^{\prime}\right)$ from (17). Then we have

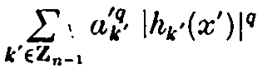

$\leqq \sum_{m=-\infty}^{\infty} \sum_{k^{\prime} \in \mathbb{Z}_{n-1}} a_{k^{\prime}}^{q}\left|\left(F^{-1} \psi_{\left(k^{\prime}, n\right)} F f\right)\left(x^{\prime}, 0\right)\right|^{q}$

$\leqq c \sum_{m=0}^{\infty}\left\{\sum_{k^{\prime} \in Z_{n-1}}\left[a_{k^{\prime}}^{\prime \lambda}\left(b_{m+1}-b_{m}\right)^{-1} b_{m+1}^{d \lambda} \int_{b_{m}}^{b_{m+1}}\left(\psi_{\left(k^{\prime}, m\right)} f\right)_{n}^{* \lambda}\left(x^{\prime}, . x_{n}\right) d x_{n}\right]^{q / \lambda}\right\}^{(\lambda / 4) \cdot(q / \lambda)}+\cdots$, 
where $+\cdots$ indicates a corresponding term with $m=-1,-2,-3, \ldots$ If one uses the triangle inequality for $l_{q}$, then one obtains a corresponding formula with $q>1$. We put temporarily

$$
\bar{a}_{k}=a_{k^{\prime}}^{\prime}\left(b_{m+1}-b_{m}\right)^{-1 / \lambda} b_{m+1}^{d} \quad \text { if } \quad k=\left(k^{\prime}, m\right) \text { with } \quad m \geqq 0 .
$$

Because $\frac{q}{\lambda}>1$, the first term on the right-hand side of (40) can be estimated from above by

$$
c \sum_{n=0}^{\infty}\left\{\int_{o_{m}}^{b_{m+1}}\left[\sum_{k \in \mathbb{Z}_{n-1}}^{\prime} \bar{a}_{\left(k^{\prime}, m\right)}^{q}\left(\psi_{\left(k^{\prime}, m\right)} f\right)_{n}^{* q}\left(x^{\prime}, x_{n}\right)\right]^{i / q} d x_{n}\right\}^{q / \lambda}
$$

Because $\frac{p}{\lambda}>1$, it follows from Hölder's inequality that

$$
\left\{\int_{b_{m}}^{b_{m+1}}[\ldots]^{\lambda / q} d x_{n}\right\}^{q / \lambda} \leqq\left(\int_{o_{m}}^{b_{m+1}}[\ldots]^{p / q} d x_{n}\right)^{q / p}\left(b_{m+1}-b_{m}\right)^{q \frac{p-\lambda}{p \lambda}} .
$$

Let $p \leq q$ and

$$
a_{k}=\bar{a}_{k}\left(b_{m+1}-b_{m}\right)^{\frac{1}{\lambda}-\frac{\lambda}{p}}=a_{k}^{\prime}\left(b_{m+1}-b_{m}\right)^{-\frac{1}{p}} b_{m+1}^{d}, \quad d>\frac{1}{p},
$$

with $k=\left(k^{\prime}, m\right), m \geqq 0$. Then (40), (42) and (43) yield

$$
\begin{aligned}
& \int_{\mathbf{R}_{n-1}}\left(\sum_{k^{\prime} \in Z_{n-1}} a_{k^{\prime}}^{q}\left|h_{k^{\prime}}\left(x^{\prime}\right)\right|^{q}\right)^{p / q} d x^{\prime} \leqq c \sum_{m=0}^{\infty} \int_{\mathbf{R}_{n-1}}\{\ldots\}^{p / q} d x^{\prime}+\cdots \\
& \leqq c^{\prime} \sum_{m=0}^{\infty} \int_{\mathbf{R}_{n-1}}^{b_{m+1}} \int_{b_{m}}^{b_{m}}\left[\sum_{k^{\prime} \in \mathbf{Z}_{n-1}} a_{\left(k^{\prime}, m\right)}^{q}\left(\psi_{\left(k^{\prime}, m\right)} f\right)_{n}^{* q}\left(x^{\prime}, x_{n}\right)\right]^{p / q} d x_{n} d x^{\prime}+\cdots \\
& \leqq c^{\prime} \sum_{m=0}^{\infty} \int_{\mathbf{R}_{n-1}}^{b_{m+1}} \int_{b_{m}}^{b_{m+1}}\left[\sum_{k \in Z_{n}} a_{k}^{q}\left(\psi_{k} f\right)_{n}^{* q}\left(x^{\prime}, x_{n}\right)\right]^{p / q} d x_{n} d x^{\prime}+\cdots \\
& \leqq c^{\prime} \int_{\mathbf{R}_{m}}\left[\sum_{k \in \mathbf{Z}_{n}} a_{k}^{q}\left(\psi_{k} f\right)_{n}^{* q}(x)\right]^{p / q} d x .
\end{aligned}
$$

Because $p \leqq q$ and $d>\frac{1}{p}$ it follows from the Proposition that the right-hand side of (45) can be estimated from above by $c\left\|f \mid F_{p . q}^{a}\left(\mathbf{R}_{n}\right)\right\|^{p}$. Together with (17) this yields the desired assertion, provided that $0<p \leqq q$ Q $\leqq 1$ and that $a_{k}$ and $a_{k^{\prime}}^{\prime}$ are related by (44). If $q \leqq 1$ and $p>q$ then we apply Hölder's inequality with $\frac{q}{p}+\frac{1}{\sigma}=1$ to $\sum_{m=0}^{\infty}\{\ldots\}$ in $(40)$. If follows that

$$
\sum_{m=0}^{\infty}\{\ldots\}=\sum_{m=0}^{\infty}(1+m)^{e}\{\ldots\}(1+m)^{-e} \leqq c\left(\sum_{m=0}^{\infty}(1+m)^{e(p / q)}\{\ldots\}^{p / q}\right)^{q / p}
$$

if $\varrho \sigma>1$, i.e. $\varrho>\frac{p-q}{p}$. In that case (i.e. $q \leqq 1$ and $p>q$ ) we replace (44) by.

$$
a_{k}=a_{k^{\prime}}^{\prime}\left(b_{m+1}-b_{m}\right)^{-1 / p} b_{m+1}^{d}(1+m)^{e / q}, \quad d>\frac{1}{q}
$$


with $k=\left(k^{\prime}, m\right), m \geqq 0$. 'The rest is the same as in the case $0<p \leqq q \leqq 1$. The case $q>1$ can be treated in a similar way, where one has, again two subcases, $p \leqq q$ and $p>\dot{q}$.

Step 3. Let again $q \leqq 1$. We discuss (44) and (46). We recall that $b_{0}=1$ and put $b_{m+1}-b_{m}=(1+m)^{-\delta}$ if $m=0,1,2, \ldots$ and $0<\delta<1$. Then we have $b_{m} \sim \sum_{l=1}^{m} l^{-\delta}$
$\sim(1+m)^{1-\delta}$. With $\delta$ near 1 we have

and

$$
a_{k} \sim a_{k^{\prime}}^{\prime}(1+m)^{\frac{1}{p}+e}, \quad \varepsilon>0, \quad \text { if } \quad p \leqq q \leqq 1
$$

$$
a_{k} \sim a_{k}^{\prime}(1+m)^{\frac{1}{q}+s}, \quad \varepsilon>0, \quad \text { if } q \leqq 1 \text { and } p \geqq q .
$$

The desired estimate is now a consequence of (37). Similarly one deals with the case $q>1$.

Remark 8: The question is whether our choice of the numbers $b_{m}$ in Step 3 of the last proof is optimal. Our limiting exponents $*$ from (37) are shown in Fig. 1. If one asks the same question, i.e.

$a_{\left(k^{\prime}, m\right)} \geqq c|m|^{*} a_{\left(k^{\prime}, 0\right)} \quad$ with $\quad c>0, \quad \varkappa \geqq 0, \quad k^{\prime} \in \mathbf{Z}_{n-1}$ and $m \in \mathbf{Z}_{1},$.

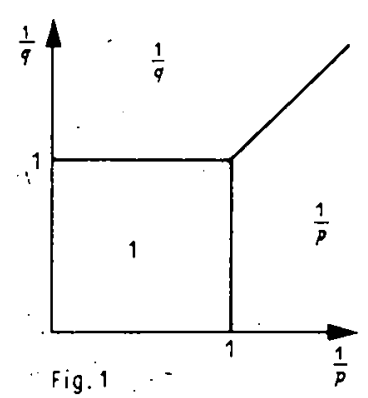

Fig. 1

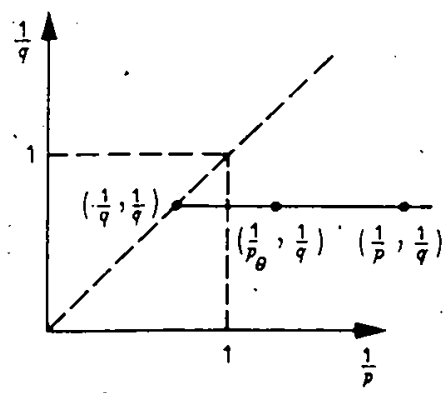

Fig. 3

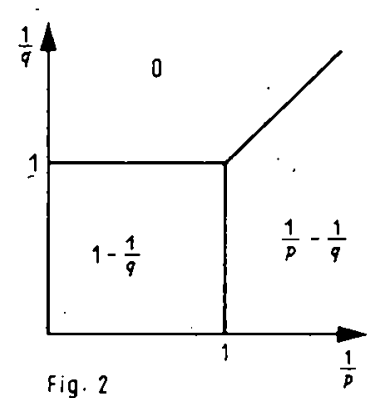

Fig. 2

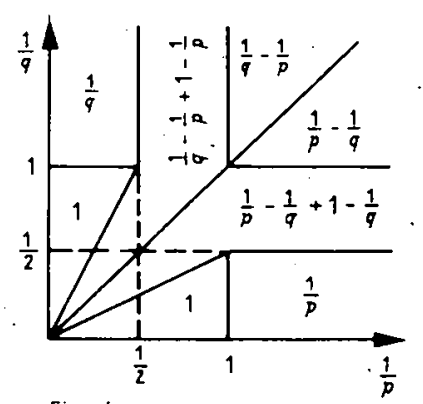

Fig. 4

for the spaces $B_{p, q}^{a}\left(\mathbf{R}_{n}\right)$ then one has to examine (15) and (16). 'The corresponding. limiting exponents $x$ are shown in Fig. 2. Becuuse $B_{p, p}^{\mathfrak{a}}\left(\mathbf{R}_{n}\right)=F_{p, p}^{\mathfrak{a}}\left(\mathbf{R}_{n}\right)$ one can try to interpolate these two figures and to improve the assertions for $F_{p, q}^{\mathrm{a}}\left(\mathbf{R}_{n}\right)$ on that way. We sketch this possibility in the following subsection. 


\subsection{Improvements}

In $[16: 2.4 .9]$ we developed a complex interpolation method which can also be applied to our situation. (One has to replace the dyadic covering of $\mathbf{R}_{n}$ by the congruent covering in the sense of the introduction.) Without any further explanations we use the notations introduced in [16:2.4.9]. In particular if $F_{p_{0 . q_{0}}}^{\mathfrak{a}^{0}}\left(\mathbf{R}_{n}\right)$ and $F_{p_{1}, q_{1}}^{\mathfrak{a}^{2}}\left(\mathbf{R}_{n}\right)$ are two spaces with the sequences $\mathfrak{a}^{0}=\left\{a_{k}{ }^{0}\right\}_{k \in Z_{n}}$ and $\mathfrak{a}^{1}=\left\{a_{k}\right\}_{k \in Z_{n}}$ then the complex interpolation $(\cdot, \cdot)_{\theta}$ with $0<\theta<1$ yields

$$
\begin{aligned}
& \left(\dot{F}_{p_{0}, q_{\theta}}^{\mathfrak{a}^{\theta}},\left(\mathbf{R}_{n}\right), F_{p_{1}, q_{1}}^{\mathfrak{a}^{1}}\left(\mathbf{R}_{n}\right)\right)_{\theta}=\dot{F}_{p_{\theta^{\prime}, q_{\theta}}^{\mathfrak{a}^{\theta}}}^{\theta^{0}}\left(\mathbf{R}_{n}\right), \\
& \mathrm{a}^{\theta}=\left\{a_{k}^{\theta}=\left(u_{k}^{0}\right)^{1-\theta}\left(a_{k}\right)^{\theta}\right\}_{k \in \mathbf{Z}_{n}}, \frac{1}{p_{\theta}}=\frac{1-\theta}{p_{0}}+\frac{\theta}{p_{1}}, \frac{1}{q_{\theta}}=\frac{1-\theta}{q_{0}}+\frac{\theta}{q_{1}} .
\end{aligned}
$$

If $a_{k}{ }^{r} \sim a_{\left(k^{\prime}, 0\right)}^{r}(1+|m|)^{x_{r}}$ with $k=\left(k^{\prime}, m\right)$ and $r=0,1$ then $a_{k}^{\theta} \sim a_{\left(k^{\prime}, 0\right)}^{\theta}(1+|m|)^{\alpha_{0}}$ with $\varkappa_{\theta}=x_{0}(1-\theta)+\varkappa_{1} \theta$ and $a_{\left(k^{\prime}, 0\right)}^{\theta}=\left(a_{\left(k^{\prime}, 0\right)}^{0}\right)^{1-\theta}\left(a_{\left(k^{\prime}, 0\right)}^{1}\right)^{0}$. If the hypotheses of Theorem 1 for $F_{q_{0}, q_{0}}^{\mathrm{a}^{\mathrm{o}}}\left(\mathbf{R}_{n}\right)=B_{q_{0}, q_{0}}^{\mathrm{a}_{0}}\left(\mathbf{R}_{n}\right)$ and the hypotheses of Theorem 2 for $F_{p_{1, q_{1}}}^{\mathrm{a}^{1}}\left(\mathbf{R}_{n}\right)$ are satisfied then we have the well-known standard situation of interpolation theory: The restriction operator $(R f)\left(x^{\prime}\right)=f\left(x^{\prime}, 0\right)$ and the extension operator ' $T$ ' from (26) are the same for both spaces. Then the interpolation property yields that $R$ is also

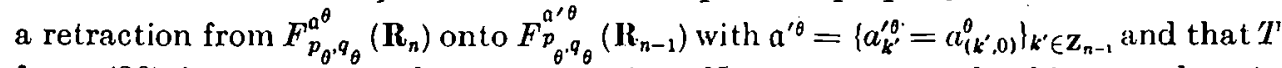
from $(26)$ is a corresponding coretraction. Now one can apply this procedure in order to improve the limiting exponents for these spaces $F_{p, q}^{\mathfrak{a}}\left(\mathbf{R}_{n}\right)$ from Fig. 1. We describe an example, cf. Fig. 3. Let $q \geqq 1$ and $p_{\theta}<q$ be given. We choose a number $p<p_{\theta}$ and determine $\theta$ such that $\frac{1}{p_{\theta}}=\frac{1-\theta}{q}+\frac{\theta}{p}$. We wish to interpolate $F_{q, q}^{a^{0}}\left(\mathbf{R}_{n}\right)=B_{q, q}^{\mathfrak{a}^{0}}\left(\mathbf{R}_{n}\right)$ and $F_{p, q}^{\mathfrak{a}^{1}}\left(\mathbf{R}_{n}\right)$ via (49) with $\frac{1}{p_{\theta}}=\frac{1-\theta}{q}+\frac{\theta}{p}$ and $q_{\theta} q$ (this corresponds to the heavy line in Fig. 3). From $p \rightarrow 0$. follows $\theta \rightarrow 0$. Now we identify $\varkappa_{0}$ and $\varkappa_{1}$ with the limiting exponents from Fig. 2 and Fig. 1, respectively, i.e. $x_{0}=1-\frac{1}{q}$ and $x_{1}=\frac{1}{p}$. Then we have

$$
\begin{aligned}
x_{\theta} & =(1-\theta) x_{0}+\theta \varkappa_{1}=(1-\theta)\left(1-\frac{1}{q}\right)+\frac{\theta}{p} \\
& =\frac{1}{p_{\theta}}+(1-\theta)\left(1-\frac{2}{q}\right) \rightarrow \frac{1}{p_{\theta}}-\frac{1}{q}+1-\frac{1}{q} .
\end{aligned}
$$

In other words: $R$ is a retraction from $F_{p_{\theta}, q}^{\mathrm{a}}\left(\mathbf{R}_{n}\right)$ onto $F_{p_{\theta}, q}^{\mathrm{a}^{\prime}}\left(\mathbf{R}_{n-1}\right)$ where $p_{\theta}$ and $q$ have the above meaning if $\mathfrak{a}=\left\{a_{k}\right\}_{k \in Z_{n}}$ with $a_{\left(k^{\prime}, m\right)} \geqq c|m|^{x} a_{\left(k^{\prime}, 0\right)}, c>0, \varkappa>\varkappa_{\theta}$, and $\mathfrak{a}^{\prime}=\left\{a_{k^{\prime}}^{\prime}=a_{\left(k^{\prime} .0\right)}\right\}_{k^{\prime} \in Z_{n-1}}$. If $1 \leqq q \leqq 2$ then this is an improvement in comparison with Theorem 2 . If we calculate the best possible limiting exponents $*$ which can be obtained on that way then we arrive at Fig. 4, which is (at least partly) an improvement of the limiting exponents from Fig. 1. However we are not sure whether these limiting exponents are natural (in contrast to the limiting exponents for the spaces $B_{p, q}^{a}\left(\mathbf{R}_{n}\right)$ from Fig. 2). 


\section{Continuous Version}

Iet $\varphi(x) \geqq 0$ be a compactly supported infinitely differentiable function on $\mathbf{R}_{n}$ with, say,

$\varphi(x)=1$ if $x=\left(x_{1}, \ldots, x_{n}\right) \in \mathbf{R}_{n}$. and $\left|x_{j}\right| \leqq 1$, where $j=1, \ldots, n$.

Let $\varphi_{y}(x)=\varphi(x-y)$ if $x \in \mathbf{R}_{n}$ and $y \in \mathbf{R}_{n}$. Of course, $\left\{\varphi_{k}(x)\right\}_{k \in \mathbf{Z}_{n}}$ is an admissible system in the sense of Section 2 after the immaterial replacement of condition (i) from Section 2 by the assumption that $\operatorname{supp} \varphi$ is compact. Roughly speaking we shall try to replace the discrete sequence $\left\{\varphi_{k}(x)\right\}_{k \in \mathbf{Z}_{n}}$ in Definition 1 of the spaces $B_{p, q}^{\mathfrak{a}}\left(\mathbf{R}_{n}\right)$ and $F_{p, q}^{a}\left(\mathbf{R}_{n}\right)$ by its continuous counterpart $\left\{\varphi_{\nu}(x)\right\}_{\nu \in \mathbf{R}_{n}}$. We extend the definition of the maximal function from (8) by

$$
\left(\varphi_{y} f\right)^{*}(\dot{x})=\sup _{z \in \mathbf{R}_{n}} \frac{\left|\left(F^{-1} \varphi_{y} F f\right)(x-z)\right|}{1+|z|^{b}}, \quad x \in \mathbf{R}_{n}, \quad y \in \mathbf{R}_{n},
$$

$f \in S^{\mathrm{c}}\left(\mathbf{R}_{n}\right)$ and $b>0$.

Theorem 3: Let $a(y)>0$ be a continuous function on $\mathbf{R}_{n}$ with

$$
a(y) \leqq c a(z) \quad \text { if } \quad y \in \mathbf{R}_{n}, \quad z \in \mathbf{R}_{n} \quad \text { and } \quad|y-z| \leqq 1,
$$

where $c>0$ is an appropriate number (which is independent of $y$ und $z$ ). Then $\dot{a}=\left\{a_{k}\right.$ $=a(k)\}_{k \in Z_{n}}$ sutisfies (5).

(i) Let $0<p \leqq \infty$ and $0<q \leqq \infty$. Let $b>\frac{n}{p}$ in (52). Then

and

$$
\left(\int_{\mathbf{R}_{n}} a^{q}(y)\left\|F^{-1} \varphi_{\nu} F f \mid L_{p}\left(\mathbf{R}_{n}\right)\right\|^{q} d y\right)^{1 / q}
$$

$$
\left(\int_{\mathbf{R}_{n}} a^{q}(y)\left\|\left(\varphi_{y} f\right)^{*} \mid L_{p}\left(\mathbf{R}_{n}\right)\right\|^{q} d y\right)^{1 / q}
$$

ure equivalent quasi-norms on $B_{p, q}^{\mathfrak{a}}\left(\mathbf{R}_{n}\right)$. (Usual modification if $\left.q=\infty\right)$.

(ii) Let $0<p<\infty$ and $0<q \leqq \infty$. Let $b>\frac{n}{\min (p, q)}$ in (52). Then

and

$$
\left\|\left(\int_{\mathbf{R}_{n}} a^{q}(y)\left|\left(F^{-1} \varphi_{\nu} F f\right)(\cdot)\right|^{q} d y\right)^{1 / q} \mid L_{p}\left(\mathbf{R}_{n}\right)\right\|
$$

$$
\left\|\left(\int_{\mathbf{R}_{n}} a^{q}(y)\left|\left(\varphi_{y} f\right)^{*}(\cdot)\right|^{q} d y\right)^{1 / q} \mid L_{p}\left(\mathbf{R}_{n}\right)\right\|
$$

ure equivalent quasi-norms on $F_{n, q}^{\mathrm{a}}\left(\mathbf{R}_{n}\right)$. Usual modification if $\left.q=\infty\right)$.

Proof: Step 1. It is obvious that the sequence a satisfies (5). We prove (i). By the multiplier theorem from [16: 1.5.2 or 1.6.3] it follows that there exists a positive number $c$ such that

$$
\left\|F^{-1} \varphi_{\nu} F f\left|L_{p}\left(\mathbf{R}_{n}\right)\|\leqq c\| F^{-1} \varphi_{k} F f\right| L_{p}\left(\mathbf{R}_{n}\right)\right\|+\cdots
$$

for all $y \in \mathbf{R}_{n}$ and all $f \in S^{\mathrm{c}}\left(\mathbf{R}_{n}\right)$, where $k \in \mathbf{Z}_{n}$ is the nearest lattice point to $y$, and $+\cdots$ indicates terms with $F^{-1} \varphi_{l} F f$ where $l \in \mathbf{Z}_{n}$ and $|l-k| \leqq c^{\prime}$ (the constant $c^{\prime}$ depends only on $\varphi$ ). Conversely, if $k \in \mathbf{Z}_{n}$ and $y \in \mathbf{R}_{n}$ with $|k-y| \leqq 1$, then we have by the same multiplier theorem that there exists an appropriate positive number $c$ 
such that

$$
\left\|F^{-1} \phi_{k} F f\left|L_{p}\left(\mathbf{R}_{n}\right)\|. \leqq c\| F^{-1} \phi_{y} F f\right| L_{p}\left(\mathbf{R}_{n}\right)\right\|+\cdots
$$

for all $f \in S^{\mathbf{c}}\left(\mathbf{R}_{n}\right)$. Here $+\cdots$ indicates terms with $\varphi_{y+e}$ instead of $\varphi_{y}$, where $\varrho \in \mathbf{Z}_{n}$ and $|\varrho| \leqq c^{\prime}$ (again $c^{\prime}$ depends only on $\varphi$ ). Integration over $y$ with $|k-y| \leqq 1$ in (59), multiplication with $a(y)$, resp. $a(k), q$-power summation over $k$ and a similar procedure starting with (58) show that (54) is an equivalent quasi-norm on $B_{p . q}^{a}\left(\mathbf{R}_{n}\right)$. Under the same hypotheses as in (58) and with the same interpretation of $+\cdots$ we have

$$
\left(\bar{\varphi}_{\nu} f\right)^{*}(x) \leqq c\left(\varphi_{k} f\right)^{*}(x)+\cdots, \quad x \in \mathbf{R}_{n} .
$$

This follows from formula (1.6.3/2) in [16]. Similarly we have

$$
\left(\varphi_{k} f\right)^{*}(x) \leqq c\left(\varphi_{\nu} f\right)^{*}(x)+\cdots, \quad x \in \mathbf{R}_{n},
$$

under the same hypotheses as in (59) (and with the same interpretation of $+\cdots$ ). By the Proposition from Section 2 and the above described procedure follows that (55) is an equivalent quasi-norms on $B_{p . q}^{\mathfrak{a}}\left(\mathbf{R}_{n}\right)$.

Step 2. We outline the proof of (ii). By the above procedure it follows from (60), (61) and the Proposition from Section 2 that (57) is an equivalent quasi-norm on $F_{p, q}^{a}\left(\mathbf{R}_{n}\right)$. Of course, the quasi-norm in (56) can be estimated from above by the quasinorm in (57), and hence by $c\left\|f \mid F_{p, q}^{a}\left(\mathbf{R}_{n}\right)\right\|$. The proof is complete if we can find a constant $c$ such that

$$
\begin{aligned}
& \left\|\left(\sum_{k \in \mathbf{Z}_{n}} a^{q}(k)\left|\left(F^{-1} \varphi_{k} F f\right)(\cdot)\right|^{q}\right)^{1 / q} \mid L_{p}\left(\mathbf{R}_{n}\right)\right\| \\
& \quad c\left\|\left(\left.\int_{\mathbf{R}_{n}} a^{q}(y) j\left(F^{-1} \varphi_{\nu} F f\right)(\cdot)\right|^{q} d y\right)^{1 / q} \mid L_{p}\left(\mathbf{R}_{n}\right)\right\|
\end{aligned}
$$

holds for all $f \in S^{\mathrm{c}}\left(\mathbf{R}_{n}\right)$. For the purpose we introduce

$$
\psi_{k}(x)=\int_{|y-k| \leqq 1} \varphi_{y}(x) d y, \quad k \in \mathbf{Z}_{n} .
$$

Then $\left\{\psi_{k}(x)\right\}_{k \in Z_{n}}$ is an admissible system in the sense of Section 2 (again with an immaterial modification of condition (i) from Section 2). In particular, the left-hand side of (62) can be estimated from above by a corresponding quasi-norm with $\psi_{k}$ instead of $\varphi_{k}$. We have

$$
\left(F^{-1} \psi_{k} F f\right)(x)=\int_{|y-k| \leqq 1}\left(F^{-1} \varphi_{y} F f\right)(x) d y
$$

If ' $q \geqq 1$ then Hölder's inequality yields

$$
\left|\left(F^{-1} \psi_{k} F^{\prime} f\right)(x)\right|^{q} \leqq c \int_{|y-k| \leq 1}\left|\left(F^{-1} \varphi_{k} F f\right)(x)\right|^{q} d y .
$$

and (62) follows easely. If $0<q<1$ then we obtain from $(63)$ and (60) that

$$
\left|\left(F^{-1} \psi_{k} F f\right)(x)\right| \leqq c \int_{|y-k| \leqq 1}\left|\left(F^{-1} \varphi_{\nu} F f\right)(x)\right|^{q} d y\left(\left(\varphi_{k} f\right)^{* 1-q}(x)+\cdots\right),
$$

where $+\cdots$ has the same meaning as in (60). By Hölder's inequality with $q+(1-q)$ $=1$ we have

$$
\begin{aligned}
& \sum_{k \in Z_{n}} a^{q}(k)\left|\left(F^{-1} \psi_{k} F f\right)(x)\right|^{q} \\
& \leqq\left(\sum_{k \in Z_{n}} a^{q}(k) \int_{|y-k| \leq 1}\left|\left(F^{-1} \varphi_{y} F f\right)(x)\right|^{q} d y\right)^{q}\left(\sum_{k \in Z_{n}} a^{q}(k)\left(\varphi_{k} f\right)^{* q}(x)\right)^{1-q}+\cdots
\end{aligned}
$$


Now it follows from (62), a second application of Hölder's inequality with. respect to $p q+p(1-q)=p$ and the Proposition from Section 2 that

$$
\begin{aligned}
& \left\|f \mid F_{p, q}^{\mathfrak{a}}\left(\mathbf{R}_{n}\right)\right\| \\
& \left.\leqq c \|\left(\int_{\mathbf{R}_{n}} a^{q}(y)\left|\left(F^{-1} \varphi_{y} F f\right)(\cdot)\right|^{q} d y\right)\right)^{1 / q}\left|L_{p}\left(\mathbf{R}_{n}\right)\|\|^{q}\left\|f \mid F_{p, q}^{\mathbf{a}}\left(\mathbf{R}_{n}\right)\right\|^{1-q},\right.
\end{aligned}
$$

which yields the desired inequality.

\section{REFERENCES}

[1] Буренков, В. И.: О разбиениях единицы. Труды мат. ин-та им. В. А. Стеклова AH CCCP 150 (1979), 24-30.

[2] Feichtinger, H. G.: Banach convolution algebras of Wiener's type. In: Proc. Conf. "Functions, Series, Operators", Budapest 1980 (to appear).

[3] Frichitivg ER, H. G.: Banach spaces of distributions of Wiener's type and interpolation. In: Proc. Conf. Oberwolfach 1980 "Functional Analysis and Approximation". ISNM 60, Birkhäuser Verlag: Basel 1981, pp. 153-156.

[4] Feicntinger, H. G.: Strong almost periodicity and Wiener type spaces. In: Proc. Conf. "Constructive Function Theory", Varna 1981 (to appear).

[5) Feichtixger, H. G.: Modulation spaces on locally compact abelian groups. Preprint: Univ: Vienna 1982.

[6] Feichtinger, H. G.: Banach spaces of distributions having a pointwise and a convolutive module structure. Preprint: Univ. Vienna 1982.

[7] Feichtixgar, H. G., and P. Gröbśer: Banach spaces of distributions defined by decomposition methods. Preprint: Univ. Vienna 1982.

[8] Гольцман, М. Л.: Описание следов для некоторых функциональных пространств. Труды мат. ин-та им. В. А. Стеклова АН СССР 150 (1979), 90-127.

[9] Гольдман, М. II.: Метод нокрытиін для описания общих пространств типа Бесова. Труды мат. ин-та им. В. А. Стенлова АН СССР 156 (1980), 4.7-81.

[10] Jarsox, S.: Generalizations of Lipschitz spaces and an application to Hardy spaces and bounded mean oscillation. Duke Math. J. 47 (1980), 959-982.

[11] КАліябин, Г. А.: Описание сле;ов для анизотропных пространств типа Трибели JІизоркина. Труды мат. ин-та им. В. А. Стеклова АН СССР 150 (1979), 160-173.

[12] Кальябин, Г. А.: Оппсания функцй из классов типа Бесова-Јизоркина-Трибеля. Труды мат. ин-та им. В. А. Стеклова АН СССР 1з6 (1980), 83-109.

[13] Peftre, J.: New Thoughts on Besov Spaces. Duke Univ. Math. Series I. Duke Univ.: Durham 1976.

[14] Triebel, H.: Fourier Analysis and Function Spaces. Teubner-Texte Math. 7, BSB B. G. Teubner Verlagsgesellschaft: Leipzig 1977.

[15] Treiebre, H.: Spaces of Besov-Hardy-Sobolev Type. Teubner-Texte Math. 15, BSB B. G. Teubner Verlagsgesellschaft: Leipzig 1978.

[16] Trimber; H.:- Theory of Function Spaces. BSB B. G. Teubner Verlagsgesellśchaft (Leipzig) and Birkhäuser Verlag (Boston) 1983.

Manuskripteingang: 26. 10.1982

\section{VERFASSER :}

Prof. Dr. Hass T'riebet

Sektion Mathematik der Friedrich-Schiller-Universitiit

DDR-6900 Jena, Universitïts.Hochhaus 